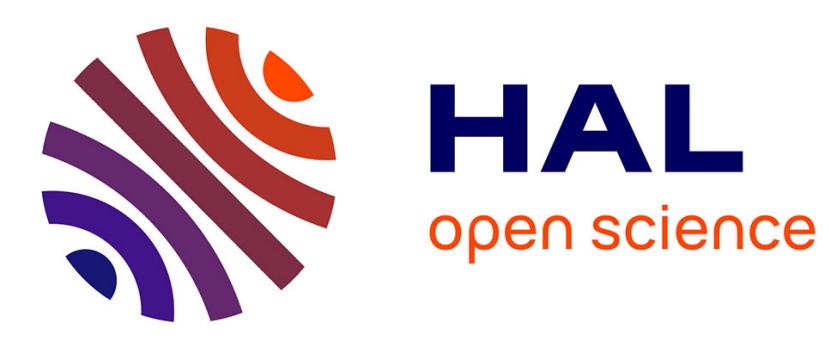

\title{
External Validity of Randomized Controlled Trials in Severe Asthma
}

\author{
Laurie Pahus, Khuder Alagha, Tünde Sofalvi, Isabelle Vachier, Arnaud \\ Bourdin, Nicolas Molinari, Pascal Chanez
}

\section{To cite this version:}

Laurie Pahus, Khuder Alagha, Tünde Sofalvi, Isabelle Vachier, Arnaud Bourdin, et al.. External Validity of Randomized Controlled Trials in Severe Asthma. American Journal of Respiratory and Critical Care Medicine, 2015, 192 (2), pp.259 - 261. 10.1164/rccm.201502-0391LE . hal-01763173

\section{HAL Id: hal-01763173 \\ https://hal.umontpellier.fr/hal-01763173}

Submitted on 4 Feb 2020

HAL is a multi-disciplinary open access archive for the deposit and dissemination of scientific research documents, whether they are published or not. The documents may come from teaching and research institutions in France or abroad, or from public or private research centers.
L'archive ouverte pluridisciplinaire $\mathbf{H A L}$, est destinée au dépôt et à la diffusion de documents scientifiques de niveau recherche, publiés ou non, émanant des établissements d'enseignement et de recherche français ou étrangers, des laboratoires publics ou privés. 


\section{External Validity of Randomized Controlled Trials in Severe Asthma}

\section{To the Editor:}

Randomized controlled trials (RCTs), because they are evidence based, are the most reliable way to assess the efficacy and safety of

Author Contributions: Conception and design: L.P., K.A., T.S., I.V., A.B., N.M., and P.C.; analysis and interpretation: L.P., K.A., T.S., I.V., A.B., N.M. and P.C.; redaction: L.P.; and corrections: K.A., T.S., I.V., A.B., N.M., and P.C.

\section{Selection of RCTs on clinicaltrials.gov: \\ - Interventional \\ - Recruiting \\ - Efficacy primary endpoint}

\section{Key words: \\ - Severe asthma \\ - Uncontrolled asthma \\ - Refractory asthma \\ - Difficult asthma

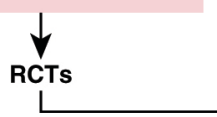

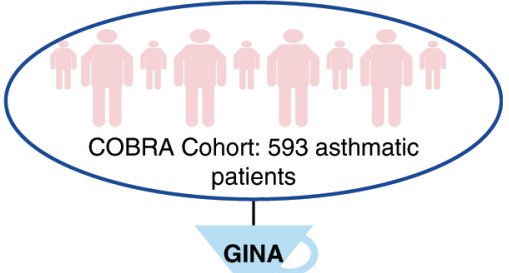
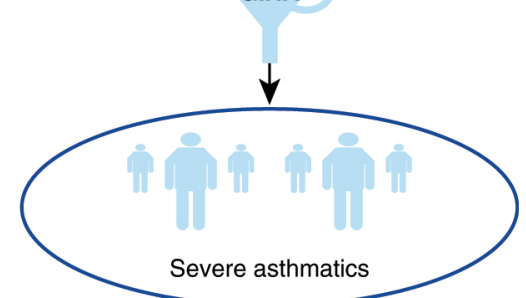

Eligibility criteria

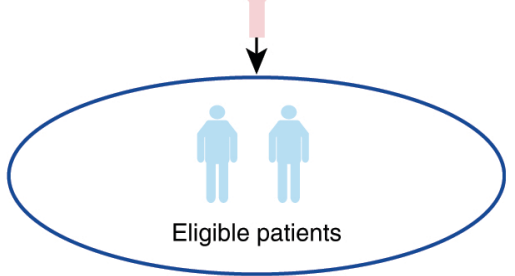

Figure 1. Methods used to determine the eligibility of patients in each clinical trial. COBRA = Cohorte Obstruction Bronchique et Asthme; GINA = Global Initiative for Asthma; RCTs = randomized controlled trials.

a new drug. This high level of evidence relies on strong methodology and a strict legislative framework. Both are carefully reviewed and approved by regulatory agencies and ethics committees before the enrollment of patients can begin.

Despite all these requirements, however, there is no guarantee that study subjects are representative of the population seen in clinical practice, and thus, there is no guarantee of the applicability of a trial's results.

One of the most common criticisms leveled at clinical trials is that they lack external validity because of their narrow eligibility criteria and that their results only apply to a small, selected population (1-6).

The purpose of the present study is to quantify the real-life population representation in RCTs studying severe asthma. We report the most discriminating criteria from RCTs that could compromise their applicability to real-life patients.
Patients' data. We used a dataset from patients taken from the academic COBRA (Cohorte Obstruction Bronchique et Asthme) cohort (Figure 1). A total of 593 patients with asthma were enrolled in this ethically approved French asthma-clinic cohort, all of whom had been thoroughly investigated and followed up. Patients had been recruited by departments of respiratory disease in French university hospitals, which commonly enroll patients in sponsored clinical trials. To enter the cohort, a patient has to consent, be diagnosed with asthma by a pulmonologist, and be younger than 80 years. Within this cohort, patients with severe asthma were identified according to the Global Initiative for Asthma (GINA) criteria (7).

RCTs. Using a clinical website (www.clinicaltrials.gov/), we exhaustively selected interventional industrial RCTs recruiting patients that had the efficacy of a drug therapy as their primary endpoint. Our keywords used were "severe asthma,"

"uncontrolled asthma," "refractory asthma," and "difficult asthma." Twelve trials were found and were classified according to the number of eligibility criteria, as reported in the Clinical Trials website (www.clinicaltrials.gov/). Trials with an incomplete profile were discarded: we assumed that those trials that required fewer than five eligibility criteria were incomplete.

All eligibility criteria used in these trials were compiled. These included demographics (age, body mass index/weight, smoking history), asthma diagnosis criteria, asthma severity, control criteria (baseline $\mathrm{FEV}_{1}$, exacerbation history, admission into an intensive care unit for asthma, asthma medications), and comorbidities criteria.

These criteria were then applied to the population of patients with severe asthma in our cohort to assess the most discriminating criteria. Subsequently, we accurately calculated the eligibility rates according to the population of patients with severe asthma represented in each RCT.

\section{Results}

The online search for trials provided us with eight assessable RCTs. We found that 303 patients with asthma of the 593 patients enrolled in the COBRA cohort (51\%) were classified as "severe" according to the GINA criteria (steps 4 and 5). Within this population of patients with severe asthma (according to the GINA criteria), the percentage of patients who would have been eligible to enter a trial ranged from 0.27 to $10.71 \%$, depending on which trial was being assessed.

Overall, $89.29-99.73 \%$ of the patients enrolled in the COBRA cohort, defined as having severe asthma, failed because of at least one eligibility criterion (Table 1). Of these, $73 \%$ failed because of insufficient airflow reversibility $\left(<12 \% \mathrm{FEV}_{1}\right.$ improvement with a bronchodilator). Minimum exacerbation rate in the previous year was the second most discriminating criterion, responsible for exclusion of $58 \%$ of patients with severe asthma. When daily intake of oral corticosteroids was an exclusion criterion, $50 \%$ of the severe COBRA patients were ineligible. A history of intensive care unit admissions for asthma excluded $31 \%$ of patients. Maximum and minimum $\mathrm{FEV}_{1}$ excluded 24 and $23 \%$ of patients, respectively. Only $77 \%$ of patients with severe asthma fulfilled the "smoking status" criterion. Finally, 3 and $2 \%$ of patients failed the body mass index/weight and comorbidities criteria, respectively. 
Current pregnancy or breastfeeding, negative methacholine challenge, and an Asthma Control Questionnaire (8) score lower than 1.5 were also exclusion criteria in some RCTs, but this information was missing from the COBRA database.

\section{Conclusions}

When the eligibility criteria for entering a RCT were applied to the clinical features of 303 patients with severe asthma, who had been well defined and thoroughly characterized in a large French national prospective cohort, we found that less than $10 \%$ were potential RCT candidates.

Many key eligibility criteria for entering RCTs are usually not considered in the daily practice of prescribing antiasthmatic

Table 1. Ranking of the Most Discriminating Criteria Used in Randomized Controlled Severe Asthma Trials

$\begin{array}{cc}\text { Patients Excluded Because of } \\ \text { Criterion } & \text { the Criterion (\%) }\end{array}$

Reversibility

Exacerbation rate

73

Absence of oral corticosteroid treatment

No ICU admission history

Maximum $\mathrm{FEV}_{1}$

Minimum FEV 1

Smoking status

Age

$\mathrm{BMI} /$ weight

Comorbidities

73
58
50

31
24
23
23
10
3
2

Definition of abbreviations: $\mathrm{BMI}=$ body mass index; ICU = intensive care unit.

Percentages are out of the total number of patients in the COBRA (Cohorte Obstruction Bronchique et Asthme) cohort.

drugs, such as age, bronchodilator reversibility, and history of or current tobacco use. Naturally, some criteria may be warranted by the trial methodology to reach the primary endpoint. For example the minimum exacerbation rate in the previous year may guarantet a sufficient number of events to avoid studies being prolonged if the primary endpoint is the time until the first exacerbation. Theseadministrative and financial constraints should not, however, affect the scientific value of these studies, and the results should remair able to be extrapolated to excluded populations.

Patients included in RCTs are young, are recently diagnosed are healthy other than their asthma, have moderate to severe rathe. than very severe asthma, and have never been heavy smokers. Because current guidelines such as GINA rely on results from sucl exclusive RCTs, this calls into question the extent to which these guidelines are applicable to daily practice.

\author{
Author disclosures are available with the text of this letter at \\ www.atsjournals.org. \\ Laurie Pahus, Pharm.D. \\ Khuder Alagha, M.D. \\ Tünde Sofalvi, M.D. \\ Assistance Publique-Hôpitaux de Marseille \\ Marseille, France \\ and \\ Aix Marseille Université \\ Marseille, France \\ Isabelle Vachier, Ph.D. \\ Hôpital Arnaud de Villeneuve \\ Montpellier, France

\begin{abstract}
Arnaud Bourdin, M.D., Ph.D.
Hôpital Arnaud de Villeneuve

Montpellier, France

Université de Montpellier 1, 2

and

National de Recherche Scientifique Unité Mixte de Recherche 9214

Montpellier, France
\end{abstract} \\ Montpellier, France \\ Institut National de la Santé et de la Recherche Médicale U1046-Centre
}

Nicolas Molinari, Ph.D.

Hôpital la Colombièrea

Montpellier, France

Pascal Chanez, M.D., Ph.D.

Assistance Publique-Hôpitaux de Marseille

Marseille, France

Institut National de la Santé et de la Recherche Médicale U1067-Centre

National de Recherche Scientifique Unité Mixte de Recherche 7333

Marseille, France

and

Aix Marseille Université

Marseille, France

On behalf of the COBRA consortium

\section{References}

1. Rothwell PM. External validity of randomised controlled trials: "to whom do the results of this trial apply?" Lancet 2005;365:82-93.

2. Town I. Applying the results of randomised control trials on asthma. Thorax 2007;62:195-196.

3. Costa DJ, Amouyal M, Lambert P, Ryan D, Schünemann HJ, Daures JP, Bousquet J, Bousquet PJ; Languedoc-Roussillon Teaching General Practitioners Group. How representative are clinical study patients with allergic rhinitis in primary care? J Allergy Clin Immunol 2011;127:920-926.

4. Scichilone N, Basile M, Battaglia S, Bellia V. What proportion of chronic obstructive pulmonary disease outpatients is eligible for inclusion in randomized clinical trials? Respiration 2014;87:11-17.

5. Dowd R, Recker RR, Heaney RP. Study subjects and ordinary patients. Osteoporos Int 2000;11:533-536.

6. Ha C, Ullman TA, Siegel CA, Kornbluth A. Patients enrolled in randomized controlled trials do not represent the inflammatory bowel disease patient population. Clin Gastroenterol Hepatol 2012;10:1002-1007.

7. Global Initiative for Asthma. Global strategy for asthma management and prevention 2011 [accessed 2014 Aug 18]. Available from: http://www. ginasthma.org/guidelines-gina-report-global-strategy-for-asthma. html

8. Juniper EF, O’Byrne PM, Guyatt GH, Ferrie PJ, King DR. Development and validation of a questionnaire to measure asthma control. Eur Respir J 1999;14:902-907. 